\title{
AIN $_{X} O_{Y}$ THIN FILMS DEPOSITED BY DC REACTIVE MAGNETRON SPUTTERING
}

\author{
J. Borges ${ }^{a,{ }^{*}}$, F. Vaz ${ }^{b}$, L. Marques ${ }^{c}$ \\ Departamento/Centro de Física, Campus de Gualtar, 4710-057 Braga, Portugal \\ Tel.: + 351253604 320, Fax: + 351253604061 \\ ajoelborges@fisica.uminho.pt \\ ${ }^{b}$ fvaz@fisica.uminho.pt \\ 'Isam@fisica.uminho.pt
}

${ }^{*}$ Corresponding author. Alternative e-mail: joelborges22@gmail.com

\begin{abstract}
$\mathrm{AIN}_{\mathrm{x}} \mathrm{O}_{\mathrm{y}}$ thin films were produced by $\mathrm{DC}$ reactive magnetron sputtering, using an atmosphere of argon and a reactive gas mixture of nitrogen and oxygen, for a wide range of partial pressures of reactive gas. During the deposition, the discharge current was kept constant and the discharge parameters were monitored. The deposition rate, chemical composition, morphology, structure and electrical resistivity of the coatings are strongly correlated with discharge parameters. Varying the reactive gas mixture partial pressure, the film properties change gradually from metallic-like films, for low reactive gas partial pressures, to stoichiometric amorphous $\mathrm{Al}_{2} \mathrm{O}_{3}$ insulator films, at high pressures. For intermediate reactive gas pressures, substoichiometric $\mathrm{AlN}_{\mathrm{x}} \mathrm{O}_{\mathrm{y}}$ films were obtained, with the electrical resistivity of the films increasing with the non metallic/metallic ratio.
\end{abstract}

Keywords: Aluminium oxide, aluminium nitride; DC magnetron; reactive sputtering; morphology; structure; electrical resistivity 


\section{Introduction}

Recently, a new class of materials has become very important for several technological fields, but poorly explored, the oxynitrides: $\mathrm{MeN}_{x} \mathrm{O}_{\mathrm{y}}$ (with $\mathrm{Me}=$ metal). The importance of this class of materials is based on the fact that oxygen is much more reactive than nitrogen and, due to this higher reactivity, the addition of a small amount of oxygen to a growing transition metal nitride film induces the production of ionic metal-oxygen bonds in a matrix of roughly covalent metal-nitrogen bond. This fact creates a new structure with a large gradient in different properties, where the optical, electrical and mechanical ones may be tailored according to the particular application envisaged. The control of the oxide/nitride ratio allows tuning of the band gap, bandwidth, and crystallographic order between oxide and nitride and, in consequence, the electronic properties of materials and thus, the overall films responses.

Among the group of possible oxynitrides, aluminium oxynitride thin films $\left(\mathrm{AlN}_{\mathrm{x}} \mathrm{O}_{\mathrm{y}}\right)$ may have some interesting applications in different technologic fields, due to a wide difference in the two base materials: aluminium nitride (AIN) and aluminium oxide $\left(\mathrm{Al}_{2} \mathrm{O}_{3}\right)$. However, the available knowledge on this particular system is still much reduced and its application is still very limited. Anyway, and similarly to the other already studied oxynitride systems, the wide variation between the properties of $\mathrm{Al}_{2} \mathrm{O}_{3}$ and those of AIN opens a significant number of possible applications for the Al-N-O system, which, in a first approach, would allow to tailor the properties of the oxynitride films between those of the pure oxide and nitride films, or to combine some of their advantages by varying the concentration of aluminium, oxygen and nitrogen in the film, according to the particular application envisaged.

Aluminium nitride (AIN) is known as being a semiconductor with a large bandgap $(6.2 \mathrm{eV})$ [1] in its more stable and common hexagonal (wurtzite) crystalline structure [2]. Beyond this structure, AIN has also two kinds of cubic structures (with two different lattice parameters) [2] and it was considered, a couple of decades ago [3], as one of the best existing thermal conductors, being an important ceramic material used in many applications such as substrate in microelectronic devices. The hexagonal AIN also exhibits a high chemical stability, high hardness $(25 \mathrm{GPa})$ [4] and high electrical resistivity $\left(10^{20} \mu \Omega \mathrm{cm}\right)$ 
[5]. The thermal conductivity and electrical resistivity are even higher for the cubic AIN [2]. Polycrystalline aluminium nitride has also high dielectric strength (between 400 and $550 \mathrm{~V} \cdot \mu \mathrm{m}^{-1}$ ), which can be improved if one produce amorphous AIN [1]; a moderated dielectric constant (8.8@1 MHz) [5]; and it is an excellent piezoelectric material [6]. AIN also resists to high temperatures (melting point above $2670 \mathrm{~K}$ ) and caustic chemical etching [7]. All these physical/chemical properties allowed the use of this material in the fabrication of optical sensors (in the UV-visible region), high power and high temperature electronic devices, surface acoustic wave (SAW) devices [8], electronic packages, among several other examples.

On the other hand, aluminium oxide, or simply alumina $\left(\mathrm{Al}_{2} \mathrm{O}_{3}\right)$, is an insulator material which is commonly prepared in the form of polymorphous material, since it can exist in many metastable structures that are divided in two broad categories: a face-centered-cubic (fcc) or a hexagonal close packed (hcp) arrangement of oxygen anions. The arrangement of aluminium cations can produce different structures, those that are based in fcc packing of oxygen and those based on hcp packing of oxygen. The first case includes $\mathrm{y}-\mathrm{Al}_{2} \mathrm{O}_{3}$ and $\eta$ $\mathrm{Al}_{2} \mathrm{O}_{3}$ (cubic arrangement), $\theta-\mathrm{Al}_{2} \mathrm{O}_{3}$ (monoclinic), and $\delta-\mathrm{Al}_{2} \mathrm{O}_{3}$ (either tetragonal or orthorhombic); while in the second case we have $\alpha-\mathrm{Al}_{2} \mathrm{O}_{3}$ (trigonal), $\mathrm{k}-\mathrm{Al}_{2} \mathrm{O}_{3}$ (orthorhombic), and $\mathrm{X}-\mathrm{Al}_{2} \mathrm{O}_{3}$ (hexagonal) phases [9]. The dominant and stable phase of alumina, $\alpha-\mathrm{Al}_{2} \mathrm{O}_{3}$, possesses trigonal symmetry with rhombohedral Bravais lattice. It exhibits chemical and mechanical stability at a temperature of up to $1250 \mathrm{~K}$ and melts at $2326 \mathrm{~K}$ [10] and it is considered as the best antioxidization coating at high temperatures, being an important coating used in the metal working industry [11]. An important fact about $\alpha-\mathrm{Al}_{2} \mathrm{O}_{3}$ (or corundum phase of alumina) is that it only can be produced at temperatures above 1023 K, using Physical Vapour Deposition (PVD) techniques [11].

The particular dielectric properties of alumina allow to use it in a large variety of applications, which can vary from microelectronics and optical applications to wear resistant coatings [12], as protective films for metal reflectors, for dark mirrors, and in metal-oxide-semiconductor devices [13]. Regarding the "mixed" aluminium oxynitride films, its use is not yet very common, despite some very few examples that are known in the field of protective coatings against wear, diffusion and corrosion, optical coatings, opto- 
electronics, microelectronics [14], multilayer capacitors as dielectric [1], among others.

Taking into account that the properties of the materials significantly depend on their interdependence of composition, structure and morphology, an understanding of these relationships will be a major concern in this work. For this purpose a set of $\mathrm{Al}-\mathrm{N}-\mathrm{O}$ films was prepared and analyzed in terms of all the above items. This study will allow the establishment of limits for practical applicability of devices coated with these materials, providing new areas of application and supplying criteria for new materials design for specific applications.

\section{Experimental details}

For the present work, $\mathrm{AIN}_{\mathrm{x}} \mathrm{O}_{\mathrm{y}}$ films were deposited by reactive $\mathrm{DC}$ magnetron sputtering, in a laboratory-sized deposition system. The films were prepared with the substrate holder positioned at $70 \mathrm{~mm}$ from the target in a

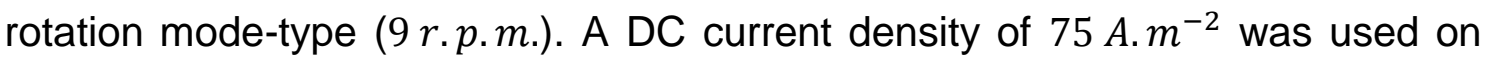
the aluminium target (99.6\% purity).

The substrates (glass, monocrystalline silicon wafers with (100) orientation, and mechanically polished high speed steel AISI M2) were grounded and kept at a constant temperature of approximately $373 \mathrm{~K}$ during the $1.5 h$ or $2 h$ deposition (using a Joule effect resistor). The temperature evolution of the coated substrates was monitored with a thermocouple placed close to the surface of the substrate holder. A delay time of five minutes was used before positioning the surface of the samples in front of the Al target. This delay time was used to avoid target poisoning resulting from previous depositions and also to assure a practically constant deposition temperature of the substrates during film growth.

The aluminium target $\left(20 \times 10 \mathrm{~cm}^{2}\right)$ was sputtered using a gas atmosphere composed of argon (working gas) and a reactive gas mixture composed of nitrogen and oxygen with a constant $\mathrm{N}_{2} / \mathrm{O}_{2}$ ratio of $17 / 3$. Before each deposition, the substrates were subjected to an etching process, using pure argon with a partial pressure of $0.3 \mathrm{~Pa}(70 \mathrm{sccm})$, a pulsed current of $0.6 \mathrm{~A}$ $\left(T_{o n}=1536 \mathrm{~ns}\right.$ and $\left.f=200 \mathrm{kHz}\right)$ for $900 \mathrm{~s}$. During the depositions, the partial 
pressure of reactive gas $\left(\mathrm{N}_{2}+\mathrm{O}_{2}\right)$ varied from 0 to $0.09 \mathrm{~Pa}$ (corresponding to a flow up to $11.25 \mathrm{sccm}$ ). The argon partial pressure was fixed at $0.3 \mathrm{~Pa}$ $(70 \mathrm{sccm})$. The discharge parameters: target potential and current, gas pressure, argon flow and reactive gas $\left(\mathrm{N}_{2}+\mathrm{O}_{2}\right)$ flow, were monitored using a National Instruments NI USB-6800 hardware plugged to a personal computer with Labview Signal Express software. To connect the power supply, the pressure sensors and the flow controller to the NI USB-6800, shielded copper cables, with $0.5 \mathrm{~mm}$ diameter, were used, and specially prepared for this acquisition system. All these instruments have analog outputs, which allowed the connections to the acquisition system. Later, this acquisition system was replaced by a Data Acquisition/Switch Unit Agilent 34970A with a multifunction module (334907A) where the cables were connected. This unit uses a RS-232 interface and the data is acquired with Benchlink Data Logger III software.

The chemical composition of the films was investigated by Rutherford Backscattering Spectrometry (RBS) with scattering angles of $140^{\circ}$ (standard detector) and $180^{\circ}$ (annular detector) and incidence angles of $0^{\circ}$ and $20^{\circ}$. Measurements were made at $2 \mathrm{MeV}$ with $\mathrm{He}^{2+}$ and, for some samples, at $1.25 \mathrm{MeV}$ with protons. The data were analyzed with the IBA DataFurnace NDF v9.3b [15].

The structure and the phase distribution of the coatings were analyzed by X-ray diffraction (XRD), using a Philips PW 1710 diffractometer (Cu-Ka radiation) operating in a Bragg-Brentano configuration. The XRD patterns were deconvoluted, assuming to be Pearson VII functions to yield the peak position, peak intensity and integral breadth. These parameters allow calculating the interplanar distance, preferential orientation and grain size.

Scanning electron microscopy (SEM) was made, to determine the thickness of the films and to catch images from the cross section of the coatings, using a Leica Cambridge 5526 apparatus.

In order to characterize the morphology of the films, beyond SEM, Atomic Force Microscopy (AFM) was used (Nanoscope III in tapping mode). The AFM images where processed by WSXM software [16].

The electrical resistivity of the conducting films was measured using the four-point probe method (in linear geometry) [17]. For the high resistivity films, 
aluminium contacts $\left(1 \times 6 \mathrm{~mm}^{2}\right)$ were vapour deposited on the top of the coating and the electrical resistivity of the films was obtained from the I-V characteristics of the metal-insulator-semiconductor (MIS) capacitor structure.

\section{Results and discussion}

\subsection{Target potential, deposition rate and morphology of the films}

Figure 1 shows the evolution of both target potential, $-V$, and deposition rate, of the different coatings as a function of the gas mixture $\left(\mathrm{N}_{2}+\mathrm{O}_{2}\right)$ partial pressure.

As it can be observed, the target potential varies from about $450 \mathrm{~V}$, for an atmosphere without reactive gas, to values between $428 \mathrm{~V}$ and $422 \mathrm{~V}$, when the reactive gas partial pressures vary from $0.01 \mathrm{~Pa}$ to $0.02 \mathrm{~Pa}$, respectively. Within this range of reactive gas partial pressures $\left(0.00 \mathrm{~Pa}<p_{\mathrm{N}_{2}+\mathrm{O}_{2}} \leq 0.02 \mathrm{~Pa}\right)$, the deposition rate remains approximately constant at a value around $35 \mathrm{~nm} \cdot \mathrm{min}^{-1}$. When the partial pressure reaches the value of approximately $0.03 \mathrm{~Pa}$, there is a significant decrease in the target potential, dropping about $11 \%$ to a value of about $374 \mathrm{~V}$. This decrease persists until a minimum value of $268 \mathrm{~V}$ is reached for a reactive gas mixture partial pressure of $0.06 \mathrm{~Pa}$. Above this pressure, the target potential remains approximately constant.

Regarding the deposition rate, figure 1 shows a significant increase of about $43 \%$, to a value of $63 \mathrm{~nm} . \mathrm{min}^{-1}$, when the partial pressure is increased from $0.02 \mathrm{~Pa}$ to $0.03 \mathrm{~Pa}$. Increasing further the reactive gas pressure, the deposition rate decreases steeply until a minimum value of about $4-5 \mathrm{~nm} \cdot \mathrm{min}^{-1}$ is reached, for a gas mixture partial pressure of $0.06 \mathrm{~Pa}$ and above.

According to the obtained results in figure 1, one might identify two main zones, with a transition zone between them. The first one - zone $M$, is observed for gas mixture partial pressures up to $0.02 \mathrm{~Pa}$, corresponding to high target potentials and relatively high deposition rates. A second zone - zone $C$ - is indexed to the films prepared with gas partial pressures of $0.06 \mathrm{~Pa}$ and above, which are characterized by low values of target potential and deposition rates. 
Between these two zones, one can consider a transition zone - zone $T$ $\left(0.03 \mathrm{~Pa} \leq p_{\mathrm{N}_{2}+\mathrm{O}_{2}} \leq 0.05 \mathrm{~Pa}\right)$, where both target potential and deposition rate are decreasing gradually.

In order to clarify these three zones evolution, one must take into account that reactive magnetron sputtering is a complex process, depending on many parameters that are commonly strongly correlated. The reactive gas used to sputter the target, not only reacts with the sputtered material in the plasma region, but also interacts with the cathode surface, leading to ion implantation or chemisorption of reactive species on the target surface. These processes modify the sputtering yield, thus affecting the deposition rate, but also the ion induced secondary electron emission coefficient of the target, which, in its turn, is closely related to the minimum sustaining discharge voltage. During reactive magnetron sputtering there are three general working regimes for the sputtered target: the first one, a so-called metallic mode, occurs when the partial pressure of reactive gas is too low to react with the metallic target, which remains clean. This induces the preparation of films with relatively high deposition rates and target voltages that can be relatively low in some cases [18], but also relatively high, such as the case demonstrated here for the aluminium oxynitrides. This would be the case demonstrated here by the samples indexed to zone M. A second regime appears as a result of the increase of the reactive gas pressure, which starts to "poison" the target surface, resulting on a decrease of its sputter yield [19], and in a decrease of the deposition rates, together with a significant variation on the target potential values. This would be the case of the films prepared in the framework of this study indexed to the transition zone. Finally, the third regime (target poisoning) occurs when the sputtered targets are close or completely poisoned, leading to a strong decrease in the sputter yield and consequently in the obtained deposition rate. In this case, the target voltages are commonly observed to be relatively low (or high) [20] in comparison to those observed for zone $M$. This would be the case of the films prepared for this study that were indexed to zone $\mathrm{C}$.

In terms of target voltage variations, it is widely known and accepted that the minimum voltage required to sustain the magnetron discharge is given by [21]: 


$$
V_{\min }=\frac{W_{0}}{\gamma_{I S E E} E \varepsilon_{i} \varepsilon_{e}}
$$

with $W_{0}$ representing the effective ionization energy; $\gamma_{I S E E}$ the ion-induced secondary electron emission coefficient $(0.091$ for aluminium, representing the number of electrons emitted per incoming ion on the target); and $E$ the effective gas ionization probability. The other two parameters, $\varepsilon_{i}$ and $\varepsilon_{e}$, are close to unit for magnetron sputtering [22], which means that the cathode voltage essentially depends on the $\gamma_{\text {ISEE }}$ coefficient [20]. The dependence of this coefficient on the reactive gas partial pressure varies for different target materials and reactive gases [22]. In the case of aluminium sputtering, the increase of the reactive gas partial pressure (oxygen/nitrogen) induces the formation of an oxide/nitride layer on the target surface, leading to an increase of the $\gamma_{I S E E}$ coefficient and the consequent decrease of the discharge voltage $(-V)$ [23-25]. This particular behavior can be used to explain the evolution of both target potential and deposition rate as a function of the reactive gas partial pressure observed in figure 1. For the case of the films indexed to zone $M$, the target remains in a clean surface state (metallic mode), corresponding to a low value of the $\gamma_{I S E E}$ coefficient thus explaining the high value of cathode voltage. The slight decrease of the target potential observed in zone $\mathrm{M}$, can be explained by the raise of the $\gamma_{I S E E}$ coefficient due to the increasing on the reactive gas ion implantation on the target. In the case of the films prepared within the transition zone (zone T), the target is most likely becoming partially oxidized, since the free Gibbs energy of formation of aluminium oxide (alumina), $\Delta G_{f, @ 298 K}^{0}\left(\mathrm{Al}_{2} \mathrm{O}_{3}\right)=-1,58 \times 10^{3} \mathrm{~kJ} \cdot \mathrm{mol}^{-1}$ is much lower than of the aluminium nitride, $\Delta G_{f \text {,@298K }}^{0}(A l N)=-2,87 \times 10^{2} \mathrm{~kJ} \mathrm{~mol}^{-1}$ [26], meaning that oxidation of the target surface predominates over nitrating. In this zone $\mathrm{T}$, the cathode voltage decreases with reactive gas pressure, due to the increase of $\gamma_{I S E E}$ coefficient as the target becomes more and more oxidized. Finally, in the case of the films prepared within zone $\mathrm{C}$, the target is completely poisoned and thus the discharge voltage reaches its minimum value, meaning that the $\gamma_{\text {ISEE }}$ coefficient is at its maximum value.

Concerning the deposition rate of the films (calculated based on SEM observations), one should note that for the same deposition time, the thickness of the samples depends on the amount of material that arrives to the substrate, 
which is correlated with the amount of atoms sputtered from the target. Since the sputter yield of a poisoned target is less than that from a metallic target, it is expected that the deposition rate decreases as the partial pressure increases until the target becomes totally poisoned. In fact, for low partial pressure of reactive gas (zone $\mathrm{M}$ ), the target remains almost metallic and the sputter yield is high, which explains the relatively high values of the deposition rate. Coming to the transition zone (zone $\mathrm{T}$ ), one might notice an unexpected jump on the deposition rate, since the target is expected to become more and more oxidized, leading to a decrease of metal atoms sputtered. This should be reflected on a deposition rate decrease. The ambiguous result observed in the plot from figure 1 (the values of the deposition rate in the transition zone are actually higher than those obtained for the films deposited within zone $M$ ), can be understood by the analysis of the SEM images shown in figures 2 a)-c). From the observation of the obtained results, one can claim that the type of growth of the films prepared within zone $T$ is significantly different from those of films from zone $M$. Whereas the zone $M$ films, have a typical columnar-like growth, the transition zone films are very porous with a cauliflower-like growth. Therefore the high deposition rates within the zone $T$ do not imply a higher quantity of material that was being deposited, but the formation of films with lower density. Further increasing the partial pressure, within the transition zone, the deposition rate is reduced as a direct consequence of the reduction of the target sputtering yield. Finally, in zone $\mathrm{C}$ the aluminium target is completely poisoned and the amount of metallic atoms sputtered is very low, thus explaining the roughly constant deposition rates in this zone.

Regarding the morphology of films, the atomic force microscopy (AFM) images reinforce the existence of the already mentioned three films zones, as can be seen from the figures $2 \mathrm{~d}$ )-f). The columnar-like growth (zone $M$ ) induces a relatively high RMS roughness $(158 \mathrm{~nm}$ ) in the films (figure $2 \mathrm{~d}$ )). The films from zone $T$ are even rougher (RMS roughness of $350 \mathrm{~nm}$ ) as it can be seen from the figure $2 e$ ), which one might find as an expected behavior if one observe the correspondent SEM image. Finally, the films from zone $C$ have relatively smooth, surfaces, with a correspondent low value of RMS roughness (3 $\mathrm{nm})$ (figure 2f)). 


\subsection{Chemical composition}

Figures 3a)-b) shows the chemical composition (at.\%) and the concentration ratios of non metallic/metallic elements of the films as a function of the partial pressure of the reactive gas mixture.

For films belonging to zone $\mathrm{M}$, prepared with low partial pressures of the reactive gas mixture $\left(p_{N_{2}+O_{2}} \leq 0.02 \mathrm{~Pa}\right)$, the concentration of aluminium decreases slightly with the increase of the reactive gas pressure, from 100 at. \% pure $\mathrm{Al}$ concentration to a value close to 90 at. \%. The concentration at. \% of oxygen and nitrogen increased slightly for these films, with the oxygen varying from 0 at. $\%$ to 8 at. $\%\left(0<C_{O} / C_{A l}<0.09\right)$; and the nitrogen from 0 at. $\%$ to 3 at. $\%\left(0<C_{N} / C_{A l}<0.04\right)$, as shown in figures $\left.3 \mathrm{a}\right)$ and $\left.3 \mathrm{~b}\right)$. The films in this zone have a characteristic metallic color, as a result of the high aluminium content and the small incorporation of nitrogen and oxygen in the films. The films within this first zone will be noted hereafter as belonging to a metallic-like zone.

Regarding the samples that were prepared with the highest gas mixture partial pressures $\left(p_{\mathrm{N}_{2}+\mathrm{O}_{2}} \geq 0.06 \mathrm{~Pa}\right.$ ), zone $\mathrm{C}$, the RBS analysis revealed that all films have very similar compositions, with an aluminium content around 40 at. \% and an oxygen amount close to 60 at. \%. The nitrogen concentration drops to a residual value (non-detectable within the resolution of the experimental setup, meaning that its amount should be below 3 to 5 at.\%. This set of results induces a roughly stoichiometric composition of the films in the form of $\mathrm{Al}_{2} \mathrm{O}_{3}$ (alumina) films. This is to be expected since the lower sputter yield of the poisoned target reduces significantly the amount of aluminium that arrive to the substrate and it is completely consumed due to high density of reactive gas in the plasma. The higher affinity of oxygen to bond aluminium compared to nitrogen, explains this non-incorporation of nitrogen in the films. In accordance with this oxide-like concentration, the films have interference-like colorations, consistent with their semi-transparency. The films within this second zone will be thus noted hereafter as belonging to a compound-like zone.

Between these two main zones, a transition region was already identified (zone T), corresponding to the films that were prepared with reactive gas partial 
pressures between $0.03 \mathrm{~Pa}$ and $0.05 \mathrm{~Pa}$. Within this transition zone, the incorporation of aluminium decreases more sharply than in zone $M$, varying from 85 at. \% to 61 at. \%. In these films the incorporation of nitrogen and oxygen becomes more important, as can be observed from the sharp increase of the $C_{O+N} / C_{A l}$ ratio up to 0.65 , with the oxygen concentration rising from $10 \mathrm{at}$. $\%$ to 21 at. \% $\left(0.12 \leq C_{O} / C_{A l} \leq 0.34\right)$ and the nitrogen content also increasing, from 5 at. \% to 18 at. \% $\left(0.06 \leq C_{N} / C_{A l} \leq 0.30\right)$. The films in this transition zone have dark grey opaque-like surface tones, which is most likely the result of their decreasing metallic content.

\subsection{Structural properties}

It is widely known and accepted that one of the most important properties of any given thin films system is its crystalline structure, which is also known as depend significantly on its particular composition. In fact, the structural features of a thin film are often used to explain not only the overall film properties, but also to develop a certain coating system with a set of required properties. In the present case, and as a result of the observed changes in composition, it is expected that the films may develop different structural features, which may then be used to scan some possible applications of the developed coatings. In order to study the phase composition of obtained thin films, X-ray Diffraction (XRD) analysis has been used. Figure 4 shows X-ray diffraction diagrams of representative $A I N_{x} O_{y}$ films, prepared within the frame of the present work. Given the three different zones of films identified previously, the obtained results revealed crystalline-like thin films within zones $M$ and $T$, and amorphoustype ones for the case of the films prepared within zone $\mathrm{C}$.

The coating deposited without reactive gas ("pure" aluminium thin film) exhibits, as expected, a face-centered cubic (fcc) structure, characteristic of aluminium [27]. The two diffraction peaks represented in figure 4 correspond to (111) and (200) planes of such fcc structure, with a clear (111) preferential growth.

A second important note is that in spite of the differences in the composition of the films within zones $\mathrm{M}$ and $\mathrm{T}$, the structure is maintained, although the peak intensity is gradually decreasing with increasing pressure of reactive gas. This 
means that the films are becoming less crystalline, ending up as completely amorphous for the highest partial pressures $\left(p_{N_{2}+O_{2}} \geq 0.06 \mathrm{~Pa}\right)$, zone $\mathrm{C}$. Furthermore, with increasing reactive gas partial pressures, the diffraction peaks also are shifting to lower diffraction angles, corresponding to higher lattice parameters, which could be a sign of the presence of some nitrogen and oxygen in interstitial positions or even substituting metallic atoms in the fcc crystalline structure of the aluminium. This change in the lattice parameter can be observed in figure 5 , where the values of the lattice parameter and grain size (estimated by XRD peak fitting with a Pearson VII function, using the integral breadth method) are plotted as a function of the chemical composition of the films. The results show that there is a general tendency for the increase of the lattice parameter as more oxygen and nitrogen is incorporated in the films. Another important fact is that the lattice parameter of the aluminium coating ( $a=4.034 \mathrm{~nm}$ for $p_{\mathrm{N}_{2}+\mathrm{O}_{2}}=0.00 \mathrm{~Pa}$ ) is lower than the reference value of this material found in the available literature [28] $\left(a_{A l}=4.0496 \mathrm{~nm}\right)$, which is a typical behavior for the films deposited by magnetron sputtering, indicating that the film is in a compressive residual stress state [29], which by its turn may result from structural defects such as interstitials, vacancies and some residual doping elements such as those of argon and oxygen. Concerning the film's grain size, the results plotted in figure 5 show that there is sharp decrease of this property as a function of the non-metallic/metallic ratio $\left(C_{O+N} / C_{A l}\right)$ in zone M, from $52 \mathrm{~nm}$ $\left(C_{O+N} / C_{A l}=0.00 \mathrm{~Pa}\right)$ to $14 \mathrm{~nm} \quad\left(C_{O+N} / C_{A l}=0.13\right)$. This decreasing can be explained by the incorporation of oxygen in the films that is segregated to the surface and grain boundaries, which inhibits the grain coarsening during columnar film growth, due to the reduced mobility of aluminium atoms on oxide layers [30]. Interesting to note for the different zones films is the behaviour that can be observed for the grain size evolution within the transition zone. In this zone, no significant variation of the grain size is reported, which assumes a value of about $30 \mathrm{~nm}$. This behavior is consistent with the formation of round shape grains whose growth is completely blocked by a surrounding oxide layer in an early stage of grain formation [30]. This is also the type of growth suggested by figure $2 b$ ). 


\subsection{Electrical Resistivity}

Electrical measurements were performed, at room temperature, and the electrical resistivity $(\rho)$ was calculated. The results are displayed in figure 6 where the electrical resistivity is plotted as a function of the non-metallic/metallic chemical ratio, $C_{O+N} / C_{A l}$.

For low values of chemical ratio $\left(C_{O+N} / C_{A l}<0.13\right)$ the electrical resistivity of the films is very low, with the values very close to aluminium bulk resistivity $\left(\rho_{A l}=2.67 \mu \Omega . \mathrm{cm}\right)$. These low resistivity values (between approximately $3 \mu \Omega . \mathrm{cm}$ and $23 \mu \Omega . \mathrm{cm})$ correspond to metallic-like zone films. Within the transition zone $\left(0.17<C_{O+N} / C_{A l}<0.65\right)$ the incorporation of nitrogen and oxygen in the lattice leads to an increase in the electrical resistivity of the films to values between $5.6 \times 10^{2} \mu \Omega \mathrm{cm}$ and $1.1 \times 10^{4} \mu \Omega$. $\mathrm{cm}$. This behavior can be explained by the decrease of the amount of free electrons in the lattice, due to reduction of the metallic content of the films. Finally, the oxide films formed $\left(C_{O+N} / C_{A l}=C_{O} / C_{A l}=1.5\right)$, belonging to the compound-like zone, exhibits an expected insulator behavior, with values of electrical resistivity between $10^{17}$ and $10^{18} \mu \Omega$. cm. The electrical resistivity of these alumina films is in agreement with the values found in the literature for alumina coatings [31, 32].

\section{Conclusion}

AIN $\mathrm{N}_{\mathrm{x}} \mathrm{O}_{\mathrm{y}}$ thin films were deposited by $\mathrm{DC}$ reactive magnetron sputtering, using an aluminium target, in an atmosphere composed of $\mathrm{Ar}$ and a mixture of nitrogen and oxygen as a reactive gas. There is a straight correlation between the discharge parameters, the deposition rate, chemical composition, morphology and structure of the films. Varying the partial pressure of reactive gas mixture, three different kinds of films were found: zone $\mathrm{M}$ - metallic-like films; zone $\mathrm{T}$ - sub-stoichiometric $\mathrm{AlN}_{\mathrm{x}} \mathrm{O}_{\mathrm{y}}$ films; and zone $\mathrm{C}$ - stoichiometric $\mathrm{Al}_{2} \mathrm{O}_{3}$ - alumina films. zone $\mathrm{M}$ occurs for low partial pressures of reactive gas, resulting on the formation of metallic films with relatively high deposition rates in a columnar-like growth and high value of RMS roughness. The grain size decreases with the increase of the non metallic/metallic ratio. The resistivity of 
these films is very low, consistent with a metallic-like behavior. Zone T (transition zone) occurs for intermediate partial reactive gas pressures, resulting on the growth of dark grey low density sub-stoichiometric $\mathrm{AIN}_{\mathrm{x}} \mathrm{O}_{\mathrm{y}}$. The grain size is independent of the chemical composition and the electrical resistivity is two/three orders of magnitude higher than zone $\mathrm{M}$ films. Within the zones $\mathrm{M}$ and $T$ the increase of oxygen and nitrogen in the films decreases the crystallinity of the fcc structure of the coatings, until a complete amorphization is obtained. Zone $\mathrm{C}$ occurs for high partial pressures of reactive gas, when the target is completely poisoned, resulting on the formation of compact semitransparent smooth thin films of alumina in stoichiometric proportions, but with very low deposition rates and very high electrical resistivity consistent with insulator-type films.

\section{Acknowledgement}

This research is sponsored by FEDER funds through the program COMPETEPrograma Operacional Factores de Competitividade and by national funds through FCT-Fundação para a Ciência e a Tecnologia, under the project PTDC/CTM/69362/2006. J. Borges acknowledges FCT for financial support under PhD grant № SFRH/BD/47118/2008.

\section{References}

[1] K.R. Bray, R.L.C. Wu, S. Fries-Carr, J. Weimer, Aluminum oxynitride dielectrics for multilayer capacitors with higher energy density and wide temperature properties, Thin Solid Films, 518 (2009) 366-371.

[2] J. Wang, W.L. Wang, P.D. Ding, Y.X. Yang, L. Fang, J. Esteve, M.C. Polo, G. Sanchez, Synthesis of cubic aluminum nitride by carbothermal nitridation reaction, Diamond and Related Materials, 8 (1999) 1342-1344.

[3] X. Qing, X. Hui, L.R. Arthur, Pressure-induced rocksalt phase of aluminum nitride: A metastable structure at ambient condition, Journal of Applied Physics, 73 (1993) 8198-8200.

[4] L. Yate, J.C. Caicedo, A.H. Macias, F.J. Espinoza-Beltrán, G. Zambrano, J. Muñoz-Saldaña, P. Prieto, Composition and mechanical properties of AIC, AIN 
and AICN thin films obtained by r.f. magnetron sputtering, Surface and Coatings Technology, 203 (2009) 1904-1907.

[5] H.C. Barshilia, B. Deepthi, K.S. Rajam, Growth and characterization of aluminum nitride coatings prepared by pulsed-direct current reactive unbalanced magnetron sputtering, Thin Solid Films, 516 (2008) 4168-4174. [6] V. Mortet, M. Nesladek, K. Haenen, A. Morel, M. D'Olieslaeger, M. Vanecek, Physical properties of polycrystalline aluminium nitride films deposited by magnetron sputtering, Diamond and Related Materials, 13 (2004) 1120-1124. [7] N. Rakov, A. Mahmood, M. Xiao, Surface metallic state of aluminum-nitride (AIN) thin films prepared by direct current (DC)-reactive magnetron sputtering: optical spectroscopic analysis with incoherent light, Scripta Materialia, 50 (2004) 589-592.

[8] Q.X. Guo, M. Yoshitugu, T. Tanaka, M. Nishio, H. Ogawa, Microscopic investigations of aluminum nitride thin films grown by low-temperature reactive sputtering, Thin Solid Films, 483 (2005) 16-20.

[9] L. Igor, B. David, Metastable Alumina Polymorphs: Crystal Structures and Transition Sequences, Journal of the American Ceramic Society, 81 (1998) 1995-2012.

[10] J.M. Schneider, W.D. Sproul, A. Matthews, Reactive ionized magnetron sputtering of crystalline alumina coatings, Surface and Coatings Technology, 98 (1998) 1473-1476.

[11] A. Aryasomayajula, S. Canovic, D. Bhat, M.H. Gordon, M. Halvarsson, Transmission electron microscopy and X-ray diffraction analysis of alumina coating by alternate-current inverted magnetron-sputtering technique, Thin Solid Films, 516 (2007) 397-401.

[12] H. Kakati, A.R. Pal, H. Bailung, J. Chutia, Deposition of nanostructured crystalline and corrosion resistant alumina film on bell metal at low temperature by rf magnetron sputtering, Applied Surface Science, 255 (2009) 7403-7407. [13] B.G. Segda, M. Jacquet, J.P. Besse, Elaboration, characterization and dielectric properties study of amorphous alumina thin films deposited by r.f. magnetron sputtering, Vacuum, 62 (2001) 27-38.

[14] S. Dreer, R. Krismer, P. Wilhartitz, G. Friedbacher, Statistical evaluation of refractive index, growth rate, hardness and Young's modulus of aluminium oxynitride films, Thin Solid Films, 354 (1999) 43-49. 
[15] N.P. Barradas, C. Jeynes, R.P. Webb, Simulated annealing analysis of Rutherford backscattering data, Applied Physics Letters, 71 (1997) 291-293. [16] I. Horcas, R. Fernandez, J.M. Gomez-Rodriguez, J. Colchero, J. GomezHerrero, A.M. Baro, WSXM: A software for scanning probe microscopy and a tool for nanotechnology, Review of Scientific Instruments, 78 (2007) 013705. [17] A.W. Robert, An algorithm for computing linear four-point probe thickness correction factors, Review of Scientific Instruments, 72 (2001) 3580-3586. [18] P. Carvalho, F. Vaz, L. Rebouta, L. Cunha, C.J. Tavares, C. Moura, E. Alves, A. Cavaleiro, G. Ph, E.L. Bourhis, J.P. Riviere, J.F. Pierson, O. Banakh, Structural, electrical, optical, and mechanical characterizations of decorative ZrO[sub x]N[sub y] thin films, Journal of Applied Physics, 98 (2005) 023715. [19] I. Safi, Recent aspects concerning DC reactive magnetron sputtering of thin films: a review, Surface and Coatings Technology, 127 (2000) 203-218. [20] D. Depla, J. Haemers, R. De Gryse, Discharge voltage measurements during reactive sputtering of oxides, in: Thin Solid Films, 2006, pp. 468-471. [21] J. A. Thornton, Magnetron sputtering: basic physics and application to cylindrical magnetrons, Journal of Vacuum Science and Technology, 15 (1978) 171-177.

[22] D. Depla, G. Buyle, J. Haemers, R. De Gryse, Discharge voltage measurements during magnetron sputtering, Surface and Coatings Technology, 200 (2006) 4329-4338.

[23] D. Depla, R. De Gryse, Target poisoning during reactive magnetron sputtering: Part I: the influence of ion implantation, Surface and Coatings Technology, 183 (2004) 184-189.

[24] D. Depla, R. De Gryse, Target poisoning during reactive magnetron sputtering: Part II: the influence of chemisorption and gettering, Surface and Coatings Technology, 183 (2004) 190-195.

[25] S. Venkataraj, D. Severin, R. Drese, F. Koerfer, M. Wuttig, Structural, optical and mechanical properties of aluminium nitride films prepared by reactive DC magnetron sputtering, Thin Solid Films, 502 (2006) 235-239. [26] N. Jacobson, Use of Tabulated Thermochemical Data for Pure Compounds, Journal of Chemical Education, 78 (2001) 814-null. [27] R.T. Downs, K.L. Bartelmehs, G.V. Gibbs, M.B. Boisen, INTERACTIVE SOFTWARE FOR CALCULATING AND DISPLAYING X-RAY OR NEUTRON 
POWDER DIFFRACTOMETER PATTERNS OF CRYSTALLINE MATERIALS, Am. Miner., 78 (1993) 1104-1107.

[28] V.A. Lubarda, On the effective lattice parameter of binary alloys, Mech. Mater., 35 (2003) 53-68.

[29] F. Vaz, L. Rebouta, P. Goudeau, J.P. Riviere, E. Schaffer, G. Kleer, M. Bodmann, Residual stress states in sputtered Ti1-xSixNy films, Thin Solid Films, 402 (2002) 195-202.

[30] I. Petrov, P.B. Barna, L. Hultman, J.E. Greene, Microstructural evolution during film growth, Journal of Vacuum Science \& Technology A: Vacuum, Surfaces, and Films, 21 (2003) S117-S128.

[31] R.K. Bhan, A. Jain, D. Kumar, S.K. Mehta, Conduction, dielectric and interface properties of $\mathrm{Al} 2 \mathrm{O} 3$ films on GaAs deposited by the e-beam evaporation technique, Semicond. Sci. Technol., 24 (2009) 9.

[32] J. Kolodzey, E.A. Chowdhury, T.N. Adam, Q. Guohua, I. Rau, J.O. Olowolafe, J.S. Suehle, C. Yuan, Electrical conduction and dielectric breakdown in aluminum oxide insulators on silicon, Electron Devices, IEEE Transactions on, 47 (2000) 121-128. 


\section{Figure captions}

Figure 1 - Evolution of the target potential and deposition rate as a function of the partial pressure of reactive gas $\left(\mathrm{N}_{2}+\mathrm{O}_{2}\right)$.

Figure 2 - SEM images of the coatings for a) zone M (columnar-like growth), b) zone $\mathrm{T}$ (cauliflower-like growth), c) zone $\mathrm{C}$ (dense, featureless-type growth); and AFM processed images for d) zone $\mathrm{M}, \mathrm{e}$ ) zone $\mathrm{T}$ and f) zone $\mathrm{C}$.

Figure 3 - Evolution of the a) chemical composition and b) concentration ratio, as a function of the partial pressure of reactive gas $\left(\mathrm{N}_{2}+\mathrm{O}_{2}\right)$. The chemical composition of all samples was determined within an error of about 3 to 5 at. \%.

Figure 4 - XRD patterns for metallic-like and transition zone films.

Figure 5 - Grain size and lattice parameter of the crystals as a function of the concentration ratio.

Figure 6 - Electrical resistivity of the films as a function of the concentration ratio. 
Figures

Figure 1

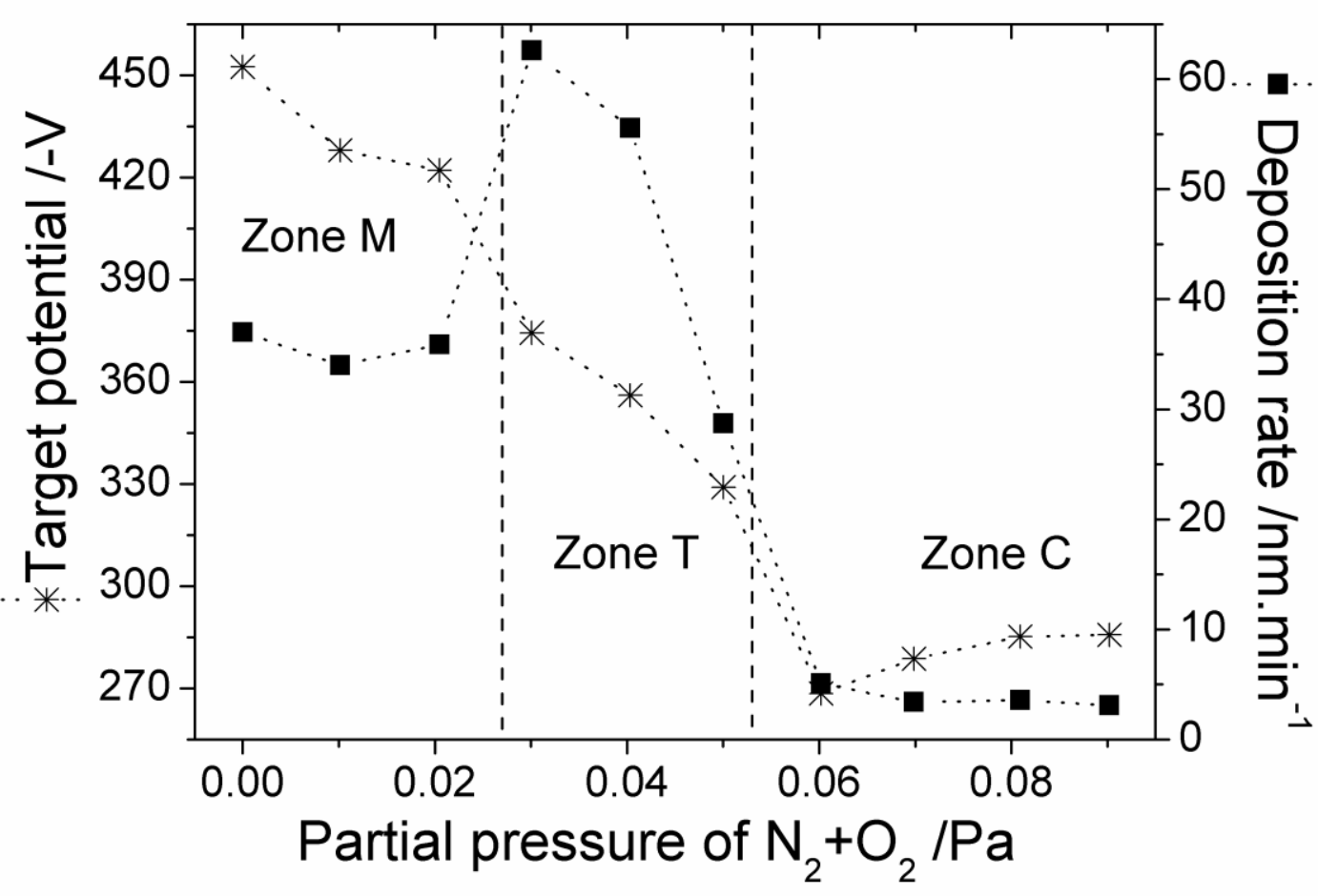


Figure 2
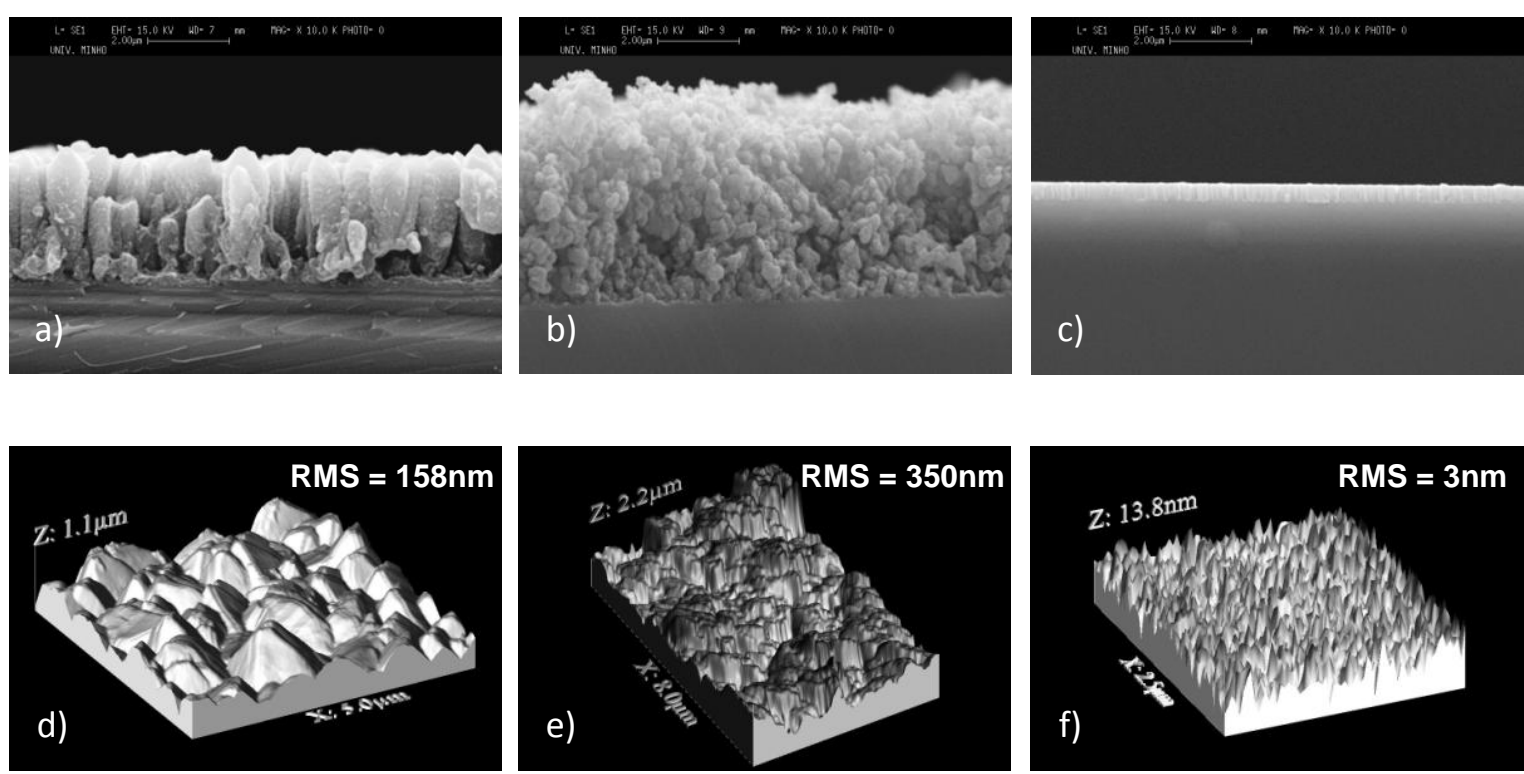
Figure 3 a)

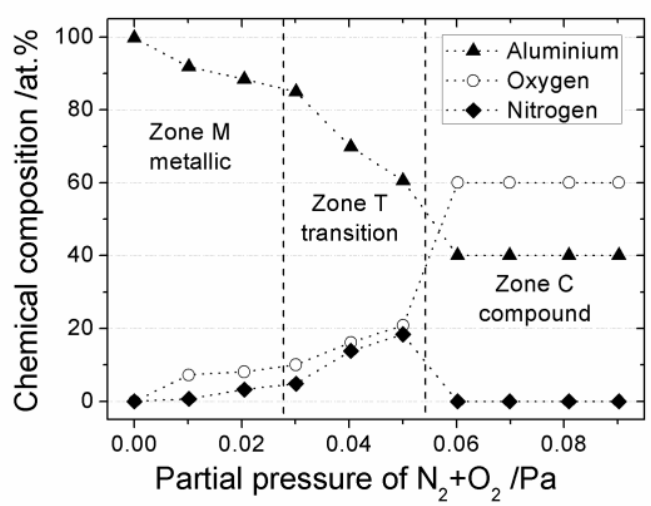

Figure $3 \mathrm{~b}$ )

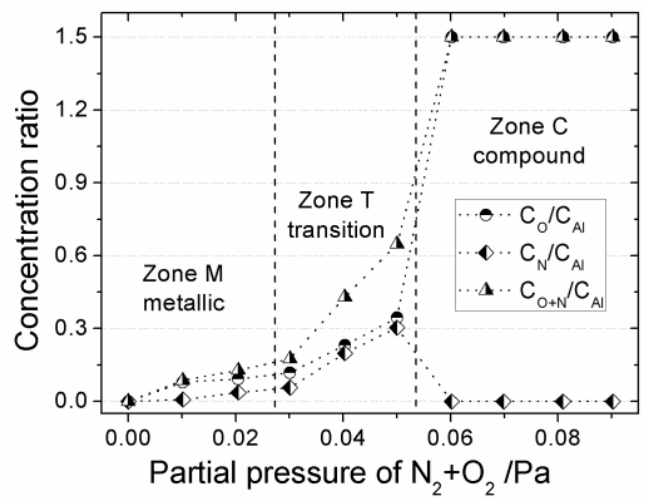


Figure 4

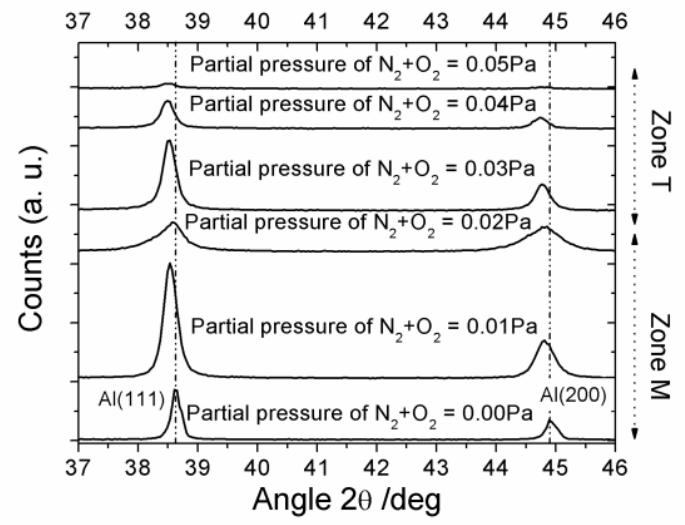


Figure 5

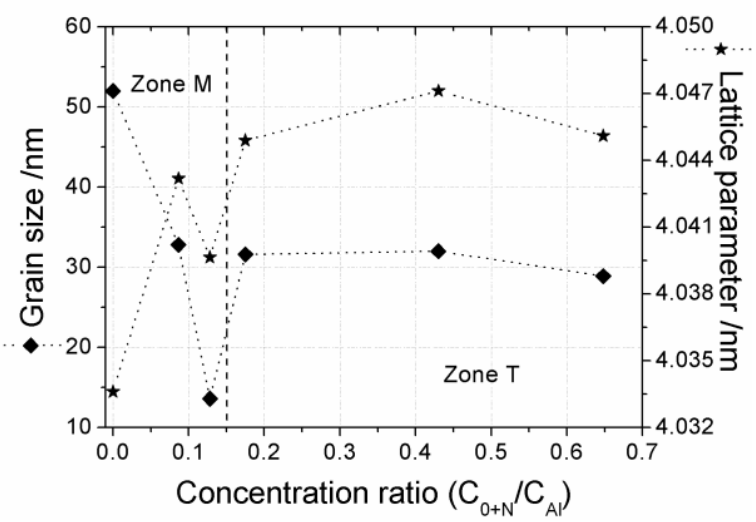


Figure 6

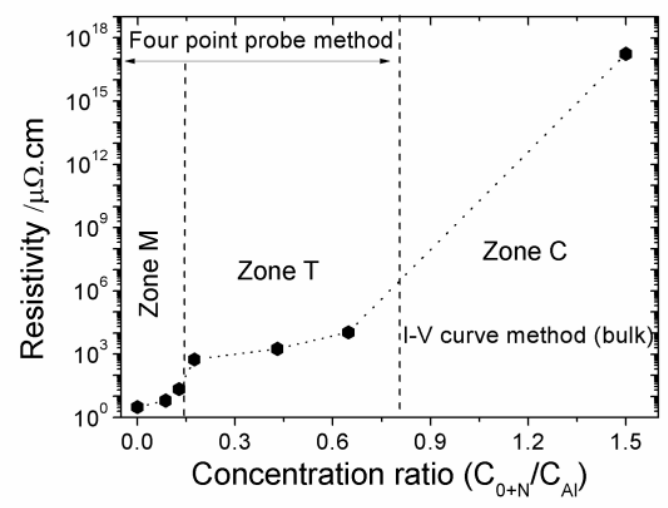

